Revista Destaques Acadêmicos, Lajeado, v. 8, n. 4, 2016. ISSN 2176-3070 DOI: http://dx.doi.org/10.22410/issn.2176-3070.v8i4a2016.1233 www.univates.br/revistas

\title{
REDES INTERDISCIPLINARES E EVENTOS EDUCACIONAIS: DIVULGANDO E DIFUNDINDO CONHECIMENTO CIENTÍFICO E TECNOLÓGICO
}

Adriana Belmonte Bergmann ${ }^{1}$, Adriana Magedanz ${ }^{2}$, Andreia Spessatto De Maman $^{3}$, Claus Haetinger ${ }^{4}$, Italo Gabriel Neide ${ }^{5}$, Jane Herber ${ }^{6}$, Marli Teresinha Quartieri ${ }^{7}$, Márcia Jussara Hepp Rehfeldt ${ }^{8}$, Miriam Ines Marchi ${ }^{9}$, Sônia Elisa Marchi Gonzatti ${ }^{10}$, Aline Patrícia Hunemeier ${ }^{11}$, Augusto Pretto Chemin ${ }^{12}$, Hélder Conceição Pacheco ${ }^{13}$

Resumo: Com o objetivo de fomentar a educação em Ciências Exatas, divulgando e difundindo o conhecimento científico e tecnológico junto à população do Vale do Taquari/RSe arredores, oportunizando a formação cidadã dos estudantes universitários, desenvolve-se, no Centro Universitário UNIVATES, o projeto de extensão "Redes Interdisciplinares - desvendando as ciências exatas e tecnológicas". Este projeto oferta

1 Licenciada em Ciências e Matemática. Mestre em Matemática Aplicada. Centro Universitário UNIVATES. Professora do CETEC.

2 Licenciada em Ciências e Matemática. Mestre em Ensino de Ciências Exatas. Centro Universitário UNIVATES. Professora do CETEC.

3 Licenciada em Ciências Exatas. Mestre em Ensino de Ciências Exatas, Centro Universitário UNIVATES. Professora do CETEC.

4 Bacharel em Matemática. Doutor em Matemática. Centro UniversitárioUNIVATES. Professor do CETEC.

5 Graduado em Física. Doutor em Física. Centro Universitário UNIVATES. Professor do CETEC.

6 Licenciada em Química. Mestre em Educação em Ciências e Matemática. Centro Universitário UNIVATES. Professora do CETEC.

7 Licenciada em Ciências e Matemática. Doutora em Educação. Centro Universitário UNIVATES. Professora do CETEC.

8 Licenciada em Ciências. Doutora em Informática na Educação. Centro Universitário UNIVATES. Professora do CETEC.

9 Bacharel em Química Industrial. Doutora em Química. Centro Universitário UNIVATES. Professora do CETEC.

10 Graduada em Ciências. Doutora em Educação. Centro Universitário UNIVATES. Professora do CETEC.

11 Graduanda em Engenharia Civil. Bolsista de Extensão. Centro Universitário UNIVATES.

12 Graduandoem Ciências Biológicas Licenciatura. Bolsista deExtensão. Centro UniversitárioUNIVATES.

13 Graduando em Química Industrial. Bolsista de Extensão. Centro Universitário UNIVATES. 
oficinas nas áreas da Matemática, Química, Física e Astronomia, além de sessões em um Planetário móvel, tendo como público alvo, principalmente, estudantes da Educação Básica, além da comunidade em geral. As mesmas atividades também são oferecidas na forma de Mostras Científicas Itinerantes, as chamadas MCIs, que extrapolam as paredes da universidade, uma vez que acontecem nos próprios espaços escolares interessados em receber a programação do Redes. Este trabalho tem por objetivo, compartilhar a experiência do desenvolvimento de três ações específicas do referido projeto: "Aprender Experimentando", "Feira de Ciências Univates: descobrindo talentos para a pesquisa" e "Olimpíada Matemática da Univates". São três eventos educacionais que divulgam e difundem o conhecimento científico e tecnológico, a fim de incentivar outros a vislumbrarem novas possibilidades pedagógicas em diferentes áreas do saber, na oferta de movimentos escolares diferenciados, que objetivam qualificar o ensino, apontando para a ruptura de espaços de aprendizagem, expandindo os mesmos para além da sala de aula, e, principalmente, incentivando e oportunizando a interligação dos saberes, reforçando aspectos pertinentes à indissociabilidade entre ensino, extensão e pesquisa.

Palavras-chave: Extensão. Interdisciplinaridade. Eventos Educacionais. Educação Básica.

\section{CONSIDERAÇÕES INICIAIS}

O projeto de extensão "Redes Interdisciplinares - desvendando as ciências exatas e tecnológicas", vinculado à Pró-Reitoria de Pesquisa, Extensão e Pós-Graduação - PROPEX e ao Centro de Ciências Exatas e Tecnológicas - CETEC, ocorre no Centro Universitário UNIVATES e tem como objetivo fomentar a educação em Ciências Exatas, divulgando e difundindo o conhecimento científico e tecnológico junto à população do Vale do Taquari/RS e arredores, oportunizando a formação cidadã dos estudantes universitários. Composto por 14 professores colaboradores e 10 bolsistas, o mesmo iniciou em 2016 a partir de um processo de discussão da nova política de extensão Institucional. Tal movimento, local, ocorre imbricado ao contexto nacional de debates, reflexões e movimentos políticos que visam a destacar e consolidar a extensão universitária como um dos eixos estratégicos da atuação das universidades. Dentre os princípios do projeto, destacam-se: a divulgação e a alfabetização científica, a interdisciplinaridade, a relação dialógica entre universidade e comunidade e o compartilhamento de saberes, em que todos os atores envolvidos aprendem e se transformam (SÍVERES, 2008).

Nesta perspectiva, o projeto Redes possui ações que articulam tanto as demandas advindas da comunidade na qual se insere, quanto as diretrizes da política Institucional de extensão. São realizadas na Instituição de Ensino Superior (IES) oficinas nas áreas da Matemática, Química, Física e Astronomia, além de sessões em um Planetário móvel, tendo como público alvo, principalmente, estudantes da Educação Básica. As mesmas atividades também são ofertadas pelo projeto na forma de Mostras Científicas Itinerantes, as chamadas MCIs, que extrapolam as paredes da universidade, uma vez que 
acontecem nos próprios espaços escolares interessados em receber as ações do Redes.

Na ótica da divulgação e difusão do conhecimento científico e tecnológico, o projeto de extensão "Redes Interdisciplinares - desvendando as ciências exatas e tecnológicas" aproxima os diálogos entre universidade e comunidade por meio de três eventos de cunho histórico e educacional, são eles: "Aprender Experimentando", "Feira de Ciências Univates: descobrindo talentos para a pesquisa" e "Olimpíada Matemática da Univates". Neste trabalho será relatado como estes eventos são concebidos, seus dados e informações, mas, mais do que caracterizar os acontecimentos, visamos conduzir o leitor a uma reflexão sobre as possíveis contribuições dos mesmos na formação do estudante da Educação Básica em âmbito escolar, mas não necessariamente dentro dos espaços da escola.

\section{APRENDER EXPERIMENTANDO}

O "Aprender Experimentando", cuja denominação traz incrustada seu principal propósito - aprender experimentando, ocorreu nos dias 03, 04 e 05 de outubro do corrente ano, nas dependências da Univates, e objetivou despertar o espírito científico, a curiosidade e o gosto pelas Ciências, por meio de atividades que visam a popularização e a difusão da ciência e tecnologia, em consonância com a proposta do projeto de extensão Redes Interdisciplinares.

Em 2016, a partir de uma parceria com o projeto de pesquisa Tendências no Ensino e apoio do CNPq por meio do edital CNPq/INSTITUTO TIM $\mathrm{N}^{\circ}$. 02/2015, foi exclusivamente voltado para os anos iniciais do Ensino Fundamental da Educação Básica, de escolas públicas e privadas da região do Vale do Taquari - RS e arredores.

As atividades foram organizadas com o intuito de que os alunos participassem dos experimentos, não apenas como observadores, mas como parte ativa e integrante do processo. "No que tange ao ensino, as atividades experimentais são frequentemente apontadas, em discussões acadêmicas, como importantes recursos didáticos das disciplinas científicas em qualquer grau de ensino" (DULLIUS, 2014, p.5).

Neste sentido, em período anterior ao evento, foram realizadas, nas escolas interessadas, formações pedagógicas com os professores dos anos iniciais, visando explorar atividades interativas, na área de Ciências Exatas, que podem ser desenvolvidas na prática através da experimentação. Cabe destacar que os experimentos realizados durante as formações supracitadas objetivaram evidenciar a inter-relação teoria e prática.

A escolha do público alvo - anos iniciais - se deu pelo direcionamento do projeto de pesquisa e também pelo fato de que muitos professores deste nível de ensino acreditam não ser necessário ensinar ciências e discutir conceitos "tão cedo". O fato de ensinar ciências gera tensões, angústias e aflições em sala de 
aula por parte de alguns docentes, pois os mesmos não tiveram formação para tal e se atêm a experimentação apenas na área da Biologia. (LIMA E MAUÉS, 2006, p. 164).

\begin{abstract}
Estudos mostram que a formação não só dos professores das séries iniciais, mas também do ensino secundário é muito teórica, compartimentada, desarticulada da prática e da realidade dos alunos. Assim, os professores têm muita dificuldade em transformar a sala de aula e criar oportunidades de aprendizagem interessantes e motivadoras para o estudo de Ciências. (MODESTO, SANTANA, VASCONCELOS; 2011, p. 3)
\end{abstract}

Acredita-se que a qualificação de professores, intermediada por metodologias interativas, além de propor uma reflexão didática, permite a significação e ressignificação dos contextos em constante transformação, que podem levar a mudanças tão consistentes que venham a propor, implementar ou até mesmo promover melhorias nos currículos de Ciências e Matemática praticados nas escolas.

Sabe-se também que nos anos iniciais "a criança vai ter o seu primeiro contato com as disciplinas, e em relação à disciplina Ciências, esse primeiro contato deve ser agradável para que o aluno possa gostar do que vai aprender" (MODESTO, SANTANA, VASCONCELOS; 2011, p. 7). Assim, torna-se importante que o professor proporcione situações que incentivem os alunos ao estudo de Ciências Exatas, o qual só acontecerá se o docente tiver conhecimento. Para Zanon e Palharini (1995), ainda é preocupante a dificuldade demonstrada por alguns professores de ciências em relacionar os conteúdos específicos com eventos da vida cotidiana.

É neste nível de ensino que são construídas (ou deveriam ser) as primeiras noções e conceitos na perspectiva da alfabetização e letramento do estudante nas áreas científica e tecnológica.

Nesta perspectiva o "Aprender Experimentando", que já vinha sendo realizado há nove anos, com edições anuais voltadas para os anos finais do Ensino Fundamental e Ensino Médio, tornou-se "Júnior", ou seja, no ano de 2016 foi exclusivamente dedicado às crianças de 6 a 10 anos de idade.

Para esse evento foram organizadas, no Centro Universitário UNIVATES, quatro salas com um total de 27 experimentos que envolviam conceitos de Química, Física e Matemática. Uma das salas foi especialmente organizada com experimentos que envolvessem a luz, em menção ao ano Internacional da Luz, comemorado em 2015 e foco do edital já citado, que fomentou a realização desta atividade.

Em cada uma destas salas estavam distribuídas diversas atividades experimentais, como: geleca, areia movediça, vulcão, chama colorida, impressão digital, telefone sem fio, luzes coloridas, o caminho da luz, campo 
magnético, jogos matemáticos, dentre outros. As atividades apresentadas tinham interlocução com conteúdos de sala de aula. Por exemplo: magnetismo, por meio de experimentações com ímãs; ótica, com diversos experimentos utilizando luz, como a reflexão em espelhos, sombras coloridas, formação de imagens; trabalho com ondas sonoras por meio de antenas; introdução de algumas ideias relacionadas as reações químicas com práticas laboratoriais, como o vulcão de lava; a demonstração do teste de chama, diferenciando substâncias em reações de queima com emissão de cores distintas; dentre outras.

Os estudantes, de $1^{\circ}$ ao $5^{\circ}$ ano, ao chegarem na IES, eram organizados em quatro grupos, um para cada sala, permanecendo em cada uma por, aproximadamente, 20 minutos, fazendo um rodízio pelas quatro salas, a fim de vivenciarem todas as experiências ofertadas. Ao final, desenhavam ou escreviam qual(is) a(s) atividade(s) foi(foram) mais apreciada(s). A Imagem 1, abaixo, possibilita visualizar alguns momentos marcantes registrados durante o evento.

Imagem 1 - Aprender Experimentando Júnior

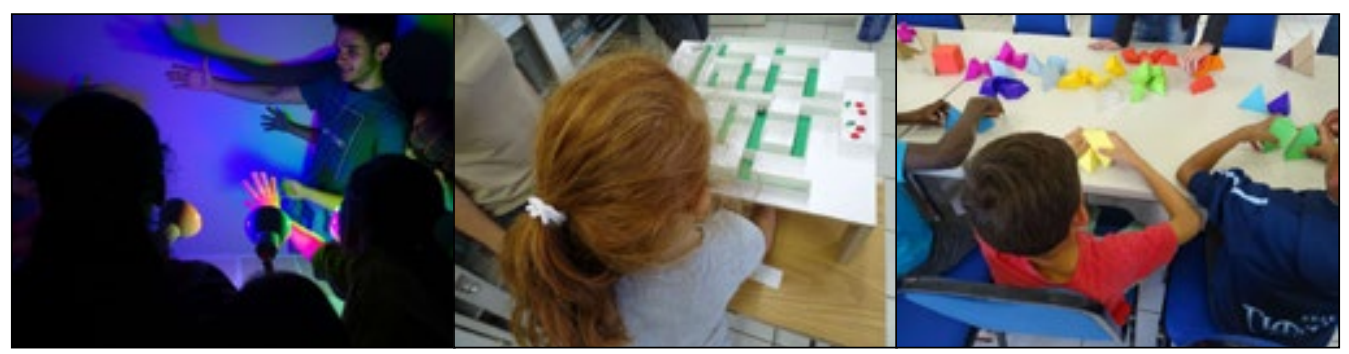

Fonte: Site do Instituto TIM (2016).

O Quadro 1 apresentado a seguir representa o resumo panorâmico das atividades relacionadas ao "Aprender Experimentando Júnior", bem como o público envolvido nas mesmas. Vale ressaltar que as escolas participantes da formação, e também os municípios atingidos, não são necessariamente os mesmos que participaram nos dias 03, 04 e 05 das atividades na IES. Para participação nestes dias foi criado um sistema de inscrições e as vagas foram sendo preenchidas por ordem de chegada das fichas de inscrição. 
Quadro 1 - Formação com professores e Aprender Experimentando Júnior em números

\begin{tabular}{|c|c|c|c|}
\hline \multicolumn{4}{|c|}{ Formação com professores (de junho a setembro de 2016) } \\
\hline Oficinas & $\begin{array}{c}\text { Escolas } \\
\text { participantes }\end{array}$ & $\begin{array}{c}\text { Municípios } \\
\text { representados }\end{array}$ & $\begin{array}{c}\text { Professores } \\
\text { participantes }\end{array}$ \\
\hline 18 & 17 & 12 & 158 \\
\hline Aprender Experimentando Júnior & (03, 04 e 05 de outubro de 2016) \\
\hline Experimentos & $\begin{array}{c}\text { Escolas } \\
\text { participantes }\end{array}$ & $\begin{array}{c}\text { Municípios } \\
\text { representados }\end{array}$ & $\begin{array}{c}\text { Alunos } \\
\text { participantes }\end{array}$ \\
\hline 27 & 19 & 11 & 889 \\
\hline
\end{tabular}

Fonte: Dos autores.

Destaca-se ainda que muitas escolas não conseguiram se inscrever, por não haver mais vaga disponível no momento da inscrição. Pode-se inferir que houve uma expressiva participação por parte dos professores em ambas atividades, tanto na formação, que ocorreu nas escolas, como nas atividades com os alunos na IES, o que evidencia que os professores querem ou, pelo menos, se interessaram por conhecer, aprender e, quem sabe, inserir atividades experimentais nas práticas pedagógicas que envolvem as áreas das Ciências Exatas nos anos iniciais do Ensino Fundamental.

\section{FEIRA DE CIÊNCIAS DA UNIVATES: DESCOBRINDO TALENTOS PARA A PESQUISA}

A "Feira de Ciências da Univates: descobrindo talentos para a pesquisa" iniciou em 2011, quando um grupo de professores do Centro Universitário UNIVATES, com apoio do Conselho Nacional de Desenvolvimento Científico e Tecnológico $(\mathrm{CNPq})$, realizou a primeira edição. A denominação "Feira de Ciências Univates: descobrindo talentos para a pesquisa" traz incrustada uma visão contemporânea de eventos deste porte - descobrir talentos para a pesquisa.

A proposta, que sempre prezou pela disseminação da cultura científica, até hoje incentiva ações interdisciplinares, por meio de abordagens quanti ou qualitativas, podendo divulgar e discutir resultados de investigações em diferentes áreas do conhecimento.

Os cinco primeiros anos de existência já registraram, aproximadamente, 250 projetos expostos, totalizando a participação de cerca de 900 estudantes da Educação Básica como expositores e 150 professores orientadores. O Quadro 2 a seguir apresenta a síntese dos dados históricos. 
Quadro 2 - Feira de Ciências da Univates em números

\begin{tabular}{|c|c|c|c|c|c|c|c|c|c|}
\hline \multirow[b]{2}{*}{$\begin{array}{l}\text { Edição } \\
\text { Feira }\end{array}$} & \multirow[b]{2}{*}{$\begin{array}{c}\mathrm{N}^{\circ} \\
\text { trabalhos } \\
\text { inscritos }\end{array}$} & \multirow[b]{2}{*}{$\begin{array}{c}\mathrm{N}^{\circ} \\
\text { trabalhos } \\
\text { expostos }\end{array}$} & \multicolumn{4}{|c|}{$\mathrm{N}^{\circ}$ escolas participantes } & \multicolumn{2}{|c|}{$\mathrm{N}^{\circ}$ de participantes } & \multirow[b]{2}{*}{$\begin{array}{c}\mathrm{N}^{\circ} \mathrm{de} \\
\text { visitantes }\end{array}$} \\
\hline & & & Lajeado & $\begin{array}{c}\text { Vale do } \\
\text { Taquari, } \\
\text { exceto } \\
\text { Lajeado }\end{array}$ & $\begin{array}{l}\text { Fora } \\
\text { Vale } \\
\text { Taquari }\end{array}$ & Total & Alunos & Professores & \\
\hline $\begin{array}{c}\text { Primeira } \\
(2011)\end{array}$ & 35 & 29 & 7 & 0 & 0 & 7 & 125 & 15 & 500 \\
\hline $\begin{array}{c}\text { Segunda } \\
(2012)\end{array}$ & 26 & 25 & 9 & 1 & 0 & 10 & 185 & 20 & 700 \\
\hline $\begin{array}{c}\text { Terceira } \\
(2013)\end{array}$ & 38 & 37 & 9 & 1 & 0 & 10 & 200 & 25 & 900 \\
\hline $\begin{array}{l}\text { Quarta } \\
(2014)\end{array}$ & 64 & 61 & 11 & 4 & 0 & 15 & 170 & 30 & 1800 \\
\hline $\begin{array}{l}\text { Quinta } \\
(2015)\end{array}$ & 127 & 102 & 11 & 18 & 2 & 31 & 265 & 55 & 2000 \\
\hline
\end{tabular}

Fonte: Dos autores.

É importante salientar que, geograficamente, o primeiro ano do evento dentro da Univates limitou-se à participação de escolas do município de Lajeado. Mas, já a partir do segundo, expandiu-se o público-alvo para cidades circunvizinhas e, hoje, a Feira de Ciências da Univates ultrapassa os limites do Vale do Taquari.

A partir de 2016, a Feira de Ciências da Univates, que busca, além de despertar novos talentos para a pesquisa, incentivar a iniciação e o espírito científico interdisciplinar dos estudantes dos ensinos fundamental, médio e técnico do Vale do Taquari e regiões circunvizinhas, passou a ter regulamento próprio. Dentre outros aspectos, a regulamentação delimitou o número de projetos a serem apresentados e expostos, incluiu a possibilidade de participação de voluntários da graduação do Centro Universitário UNIVATES nas equipes e determinou condições pontuais a serem seguidas na elaboração dos projetos inscritos.

Diante deste novo cenário, a sexta edição, realizada nos dias 06 e 07 de outubro, no Complexo Esportivo da Univates, recebeu 262 expositores, que apresentaram 80 trabalhos, dentre eles, 27 do Ensino Fundamental, 50 do Ensino Médio e 3 do Ensino Técnico.

Entre os 80 projetos em exposição, foi percebida uma extensa diversidade nas temáticas abordadas, entre estas, é possível destacar: saúde e bem-estar, meio ambiente e sustentabilidade, ensino e aprendizagem e, mesmo que em menor número, alguns trabalhos abordando sobre mitos, crenças e saberes populares, cultura popular e também igualdade social.

Esta percepção relacionada a diversidade científica é de suma importância. Segundo Chassot (2000), na contemporaneidade, ciência deve ser vista como uma linguagem. Assim, "ser alfabetizado cientificamente é saber ler 
a linguagem em que está escrita a natureza. É um analfabeto científico aquele incapaz de uma leitura do universo" (Id., 2003, texto digital).

O conhecimento empírico associado a diferentes vertentes teóricas, e vice-versa, auxiliará no exercício de compreensão que, por sua vez, devem interferir no desenvolvimento humano. Corroborando Chassot (2008, p. 73):

Entender a Ciência nos facilita, também, contribuir para controlar e prever as transformações que ocorrem na natureza. Assim, teremos condições de fazer que estas transformações sejam propostas, para que conduzam a uma melhor qualidade de vida. Isso é, por sabermos Ciência seremos mais capazes de colaborar para que as transformações que envolvem o nosso cotidiano sejam conduzidas para que tenhamos melhores condições de vida.

Neste sentido, a alfabetização científica é uma boa oportunidade dos alunos compreenderem as manifestações do universo e a proposta de organizar feiras de ciências vem ao encontro deste preceito.

Os trabalhos submetidos a Feira de Ciências da Univates são avaliados por uma comissão pré-estabelecida e, a partir do processo avaliativo que é composto pela escrita e pela exposição oral dos participantes, é realizada uma classificação por nível de ensino: fundamental, médio e técnico. Recebem menção honrosa, em cerimônia de premiação posterior, os três primeiros colocados de cada categoria e o projeto com melhor pontuação da Feira, independente do nível de ensino, é condecorado como "destaque". Além disso, os dois trabalhos com melhor classificação no ensino médio podem participar da "Mostra de Ciência e Tecnologia - MOSTRATEC", da qual a Feira de Ciências Univates é afiliada desde 2012.

Visando qualificar a escrita dos trabalhos, em 2016 foi oferecida, de forma gratuita, várias edições de uma oficina intitulada "Construindo Projetos de Pesquisa". De forma geral, os participantes desta espécie de workshop foram orientados sobre o regulamento da Feira, utilização do Manual de Trabalhos Acadêmicos da Univates como suporte na redação dos trabalhos, formatação de textos e citações, apresentação de referências, possibilidades de aprimoramento das pesquisas com o uso do Google Acadêmico, dicas pertinentes ao planejamento e elaboração de um projeto científico, além de discussões gerais levantadas pelos participantes. No total, foram atendidas, aproximadamente, 60 pessoas, entre professores, alunos, bolsistas e voluntários. A Imagem 2 abaixo reflete um pouco da movimentação presente nos dias de ocorrência da Feira de Ciências Univates. 
Imagem 2 - Feira de Ciências Univates: descobrindo talentos para a pesquisa

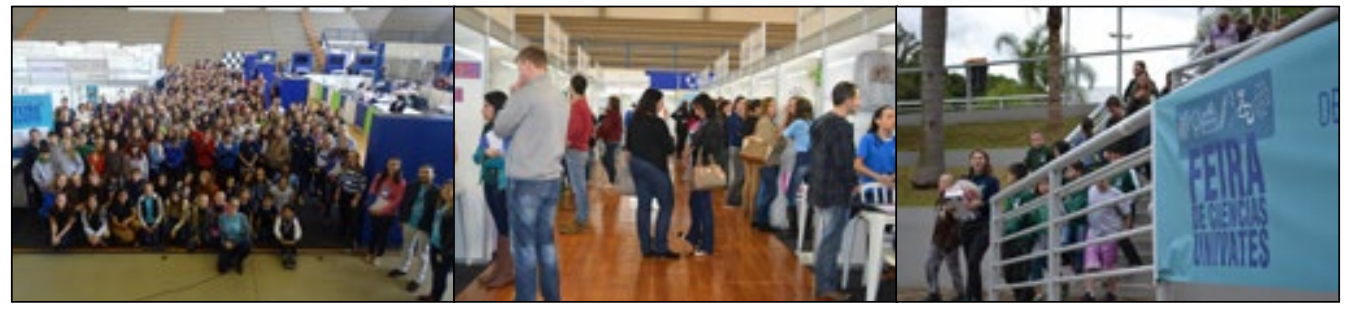

Fonte: Site do Centro Universitário UNIVATES (2016).

Alavancar os índices apresentados, sem perder a qualidade histórica, expandir as fronteiras da Feira, mantendo os incentivos às produções locais, contribuir para a investigação científica, mas de forma comprometida e regulamentada, são as principais perspectivas que norteiam, ano a ano, a continuidade e o aprimoramento desta importante ação institucional denominada "Feira de Ciências da Univates: descobrindo talentos para a pesquisa".

\section{OLIMPÍADA MATEMÁTICA DA UNIVATES - OMU}

A "Olimpíada Matemática da Univates" (OMU), que neste ano foi realizada na tarde do dia 16 de setembro, tendo por local a própria IES, está na $19^{\text {a }}$ edição. Consiste em uma prova composta por 10 questões, sendo 3 objetivas e 7 subjetivas, voltada para estudantes a partir do $5^{\circ}$ ano do Ensino Fundamental.

De acordo com Groenwald (1997), vivemos numa sociedade cada vez mais complexa, modernizada e avançada, que nos exige atualizações ininterruptas. Estendendo tal reflexão, é possível constatar que as simples operações matemáticas não são suficientes para cobrir as tecnologias e automações dos dias atuais. A Matemática se torna um ensino mais sofisticado quando reorganiza e reestrutura os pensamentos, capacitando os aprendizes a avaliar a tomada de decisões, presumindo possíveis erros e riscos. Corroborando com Dante (2009), o maior desafio da educação contemporânea é preparar cidadãos para a diversidade da vida. Por isso, os educadores precisam ajustar algumas práticas pedagógicas.

Neste contexto, desde 1999, uma equipe, composta por professores e bolsistas do Centro Universitário UNIVATES, realiza anualmente a OMU, que tem como propósito principal incentivar alunos e professores da Educação Básica a resolver problemas desafiadores e contextualizados, inserindo em sala de aula metodologias que proporcionem o desenvolvimento do raciocínio lógico-matemático, refugiando-se do ensino conteudista e burocrático de outrora. 
Desde 2003, a OMU tem como pré-requisito a Olimpíada Brasileira de Matemática (OBM), ou seja, para efetuar a inscrição na OMU, obrigatoriamente, o estudante precisa ter participado da OBM na sua escola de origem. Tal critério não é obstáculo, uma vez que ao longo dos últimos treze anos, estiveram anualmente nas dependências da Univates, aproximadamente, 2.328 estudantes para a realização da prova. $\mathrm{O}$ quadro a seguir apresenta a íntegra dos dados deste histórico supracitado.

Acompanhar o histórico numérico da OMU é um exercício que leva a refletir sobre o compromisso social do evento, já que a abrangência extrapola os limites regionais e, a cada ano, são mais de dois mil diretamente envolvidos. Em 2016, teve participação de 2.324 estudantes, sendo 1.782 do Ensino Fundamental e 542 do Ensino Médio, oriundos de 72 escolas e envolvendo 25 diferentes municípios.

A OMU, desde sua concepção até os dias de hoje, mantém na sua essência o estímulo as diferentes formas de pensar. De acordo com os Parâmetros Curriculares Nacionais (PCNs):

[...] a resolução de problemas é uma importante estratégia de ensino. Os alunos, confrontados com situações-problema, novas mas compatíveis com os instrumentos que já possuem ou que possam adquirir no processo, aprendem a desenvolver estratégia de enfrentamento, planejando etapas, estabelecendo relações, verificando regularidades, fazendo uso dos próprios erros cometidos para buscar novas alternativas; adquirem espírito de pesquisa, aprendendo a consultar, a experimentar, a organizar dados, a sistematizar resultados, a validar soluções; desenvolvem sua capacidade de raciocínio, adquirem auto-confiança e sentido de responsabilidade; e, finalmente, ampliam sua autonomia e capacidade de comunicação e de argumentação (BRASIL, 1998, p. $52)$.

As oficinas de preparação para a OMU, levadas até as escolas por meio das MCIs do projeto de extensão Redes Interdisciplinares, são uma demonstração de que o conhecimento matemático não se apoia somente em demonstrações formais. Com a utilização de material concreto para a resolução de problemas é possível desenvolver uma ampla base experimental, "que se amplia a cada problema cujo resultado for verificado com sucesso" (Polya, p.68, 1978). No Quadro 3 apresentamos alguns dados relacionados à esta atividade, de 2003 a 2015, bem como, na sequência, pode ser observado na Imagem 3, o envolvimento dos discentes na atividade a que nos referimos. 
Quadro 3-OMU em números

\begin{tabular}{|c|c|c|c|}
\hline Descrição & $\begin{array}{c}\text { Escolas } \\
\text { participantes }\end{array}$ & $\begin{array}{l}\text { Municípios } \\
\text { envolvidos }\end{array}$ & $\begin{array}{c}\text { Alunos participantes } \\
\text { Univates }\end{array}$ \\
\hline $6^{\mathrm{a}} \mathrm{OMU}$ (2003) & 66 & 25 & 2038 \\
\hline $7^{\mathrm{a}} \mathrm{OMU}(2004)$ & 72 & 26 & 2225 \\
\hline $8^{\mathrm{a}} \mathrm{OMU}(2005)$ & 93 & 35 & 2700 \\
\hline $9^{\mathrm{a}} \mathrm{OMU}(2006)$ & 87 & 31 & 2460 \\
\hline 10a OMU (2007) & 87 & 31 & 2460 \\
\hline $11^{\mathrm{a}} \mathrm{OMU}(2008)$ & 83 & 26 & 2492 \\
\hline $12^{\mathrm{a}} \mathrm{OMU}(2009)$ & 70 & 26 & 2384 \\
\hline $13^{\mathrm{a}} \mathrm{OMU}(2010)$ & 61 & 21 & 2438 \\
\hline 14a OMU (2011) & 72 & 19 & 2584 \\
\hline 15ª OMU (2012) & 70 & 24 & 2170 \\
\hline $16^{\mathrm{a}} \mathrm{OMU}$ (2013) & 81 & 28 & 2148 \\
\hline 17 OMU (2014) & 85 & 32 & 2350 \\
\hline 18 $8^{\mathrm{a}} \mathrm{OMU}$ (2015) & 65 & 25 & 2008 \\
\hline
\end{tabular}

Fonte: Haetinger, 2016, texto digital.

Imagem 3 - Olimpíada Matemática da Univates (OMU)

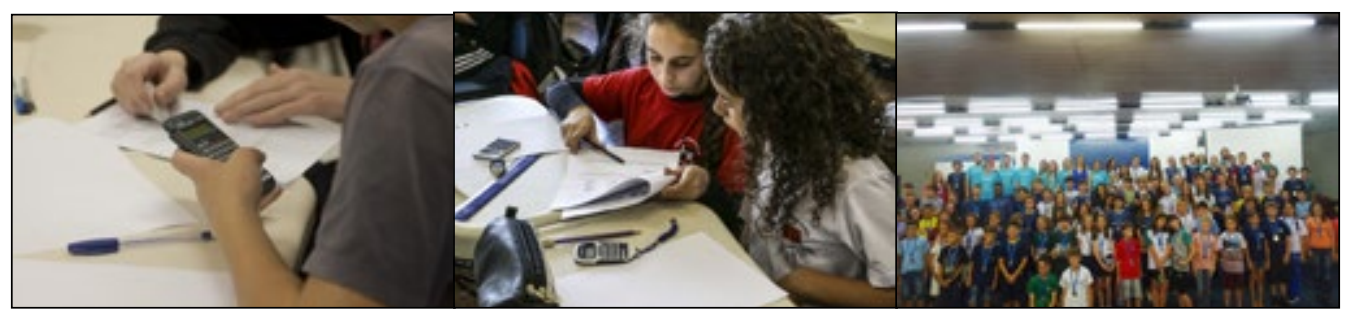

Fonte: Site do Centro Universitário UNIVATES (2016).

Após a realização da prova, uma equipe composta por professores universitários efetua a correção, apenas os três primeiros colocados de cada ano/série são agraciados com alguma premiação, os demais recebem certificados de participação.

Por fim, a OMU, enquanto incentivadora do raciocínio lógico e da criatividade na resolução de problemas, certamente traz contribuições pedagógicas e sociais incomensuráveis, não apenas no ramo da Matemática, mas na construção do conhecimento em diferentes áreas do saber e, principalmente, na interligação possível destes saberes, vislumbrando novas possibilidades nos 
diálogos entre universidade e comunidade. A Imagem 3 resume o contexto da OMU.

\section{CONSIDERAÇÕES FINAIS}

Os três eventos relacionados nesta escrita - "Aprender Experimentando Júnior", "Feira de Ciências Univates: descobrindo talentos para a pesquisa" e "Olimpíada Matemática da Univates" - são anuais. Destinados à estudantes da Educação Básica de escolas públicas e privadas, ocorrem dentro da IES e visam oferecer vivências extra-curriculares diferenciadas, auxiliando na formação do estudante, mas, em especial, fomentando, divulgando e difundindo o conhecimento científico e oportunizando momentos de interação entre escola e universidade, conforme pressupostos do projeto de extensão "Redes Interdisciplinares - desvendando as ciências exatas e tecnológicas".

As ações descritas, conectadas a conjecturas interdisciplinares, buscam contribuir no fortalecimento do diálogo entre as disciplinas (THIESEN, 2008), no desenvolvimento da alfabetização científica (CHASSOT, 2000, 2003, 2008) e na exploração de diferentes estratégias para a resolução de problemas (DANTE, 2002).

Considerando o histórico promissor destes três eventos, que de forma conjunta, somente em 2016, atingiu diretamente em torno de 3500 pessoas, sem contabilizar os reflexos indiretos, bem como o compromisso pedagógico e social que os mesmos representam nos processos de ensino e de aprendizagem, e na perspectiva de agregar na qualificação da formação inicial de todos os envolvidos no processo, é possível vislumbrar novas possibilidades na construção do conhecimento em diferentes áreas do saber, na oferta de ações que objetivam qualificar o ensino, na ruptura de espaços de aprendizagem para além da escola e, principalmente, na interligação dos saberes, reforçando aspectos pertinentes à indissociabilidade entre ensino, extensão e pesquisa.

\section{REFERÊNCIAS}

BRASIL, Secretaria de Educação Fundamental. Parâmetros Curriculares Nacionais: Ensino Médio - Matemática. Brasília, MEC/SEF, 1998. Disponível em: <portal.mec. gov.br/seb/arquivos/pdf/ciencian.pdf>. Acesso em: 28 agosto 2016.

CHASSOT, A. Alfabetização científica: questões e desafios para a educação. Ijuí: Editora Unijuí. 2000.

Alfabetização científica: uma possibilidade para a inclusão social.

Universidade do Vale do Rio dos Sinos. Revista Brasileira de Educação, Jan./Fev./ Mar./Abr. 2003. No 22.

Sete escritos sobre educação e ciência. São Paulo: Cortez, 2008. 
DANTE, L. R. Didática da resolução de problemas de matemática: 1. a 5. séries. 12 . ed. São Paulo: Ática, 2002.

. Formulação e resolução de problemas de matemática: teoria e prática. 1. ed. São Paulo: Ática, 2009.

DULLIUS, M. M. e QUARTIERI, M. T. (Org.) Aprender experimentando. Lajeado, RS: Editora Univates, 2014.

GROENWALD, C. L. O. Educação matemática de 5. a 8. séries do 1. grau: uma abordagem construtivista. [S.1.]: Salamanca, 1997.

HAETINGER, C. Olimpíada Matemática da Univates. Página pessoal. Disponível em: $<$ ensino.univates.br/ chaet/Olimpiada_Matematica_da_UNIVATES.html > Acesso em: 28 agosto 2016.

LIMA, M. E. C. C; MAUÉS, E.. Uma releitura do papel da professora das séries iniciais no desenvolvimento e aprendizagem de ciências das crianças. In Ensaio. v. 8, $\mathrm{n}^{\circ} 2$, p. 161-175. Dez/2006.

MODESTO, M. A.; SANTANA, C. G.; VASCONCELOS, A. D. O ensino de Ciências nas Séries Iniciais: relação entre teoria e prática. In anais do V Colóquio Internacional "Educação e Contemporaneidade". São Cristovão - SE, 2011.

POLYA, G. A arte de resolver problemas. Rio de Janeiro: Interciência, 1978.

SÍVERES, L. A extensão como um princípio de aprendizagem. Revista Diálogos: Universidade do Século XXI: a contribuição da extensão na busca da aprendizagem. Brasília, vol. 10, p. 8-17, 2008.

THIESEN, Juares da Silva. A interdisciplinaridade como um movimento articulador no processo ensino-aprendizagem. In: Revista Brasileira de Educação, v. 13, n. 39, set/dez 2008. p. 546 - 554.

TIM, Instituto. Formações de professores em ciência. Disponível em <institutotim. org.br/2016/12/05/formacoes-de-professores-em-ciencia> Acesso em: 15 dezembro 2016.

UNIVATES, Centro Universitário. Cerimônia reconhece os destaques da $19^{\mathrm{a}} \mathrm{OMU}$, $8^{\text {a }}$ Olinfu e Feira de Ciências. Disponível em <www.univates.br/noticias/19762> Acesso em: 15 dezembro 2016.

ZANON, L.B. e PALHARINI, E.M. A química no ensino fundamental de ciências. Química Nova na Escola, v. 2, p. 15-18, 1995. 